\title{
Refsum's syndrome: report of three cases
}

\author{
C. D. QUINLAN AND E. A. MARTIN \\ From Adelaide Hospital, Dublin
}

SUMMARY The case reports of three cases of Refsum's syndrome are presented, and the underlying metabolic abnormality discussed. The effect of treatment with a low-phytanic acid diet in one case is described.

Refsum in 1945 first described the syndrome of heredoataxia hemeralopia polyneuritiformis in a series of five cases in two unrelated families. All of these patients were the issue of consanguineous marriages. The term heredopathia atactica polyneuritiformis (HAP) was later preferred by Refsum in view of important differences from the other heredofamilial ataxias (Refsum, 1946). A number of case reports followed the definitive description (Reese and Bareta, 1950; Clark and Critchley, 1951; Ashenhurst, Millar, and Milliken, 1958; Gordon and Hudson, 1959; Alexander, 1966; Nevin, Cumings, and McKeown, 1967) but less than 50 cases have been reported in the world literature over the space of 24 years-an indication of the rarity of the condition.

The clinical features are varied, but four have become accepted as the cardinal diagnostic signsnamely, chronic polyneuritis, cerebellar ataxia, atypical retinitis pigmentosa, and an increased protein content of cerebrospinal fluid without pleocytosis. Less constant neurological features include hemeralopia, anosmia, nerve deafness, meiosis and other pupillary abnormalities, and palpable thickening of peripheral nerves. Nonneurological features frequently occur, notably a dermatosis resembling ichthyosis, cutaneous naevi, cardiomyopathy, lens opacities, and skeletal abnormalities, principally pes cavus and epiphyseal dysplasia.

Necropsies have been performed in a number of patients (Reese and Bareta, 1950; Cammermeyer, 1956; Gordon and Hudson, 1959; Alexander, 1966) with considerable uniformity in the pathological findings. Abnormalities are most pronounced in the peripheral nerves, which may be diffusely thickened macroscopically. Microscopy shows the thickening to be due to two factors: the accumulation of an exudate between the nerve bundles and within the perineurium; and an increase in fibrous tissue both in the perineural sheath and surrounding individual axons. The fibrous tissue tends to accumulate in concentric layers, forming the histological picture aptly likened to an onion bulb. Cammermeyer (1956) suggested that this appearance might well result from progressive delamination of myelin sheaths with reorientation of surviving collagen fibres, delamination being due to an inherent defect of the bonds between layers of protein and lipid.

The disease had long been thought to be associated with or due to a disorder of lipid metabolism. Refsum himself suggested that the disease was akin to the lipoidoses. The necropsy studies of Alexander (1966) indicated the presence of lipoid droplets in peripheral nerve sections as well as in other tissues including the liver and kidneys. The disorder remained undefined until Klenk and Kahlke (1963) reported the presence of abnormal concentrations of $3,7,11,15$ tetramethylhexadecanoic acid (phytanic acid) in the blood and tissues of a patient with Refsum's syndrome. This substance has been regularly identified in cases reported subsequently (Alexander, 1966; Nevin, Cumings and McKeown, 1967; Campbell and Williams, 1967). Phytanic acid is present in the blood and tissues of normal persons (Avigan, 1966), but in such minute quantities as to be undetectable by standard procedures such as gasliquid chromatography, which, therefore, provides an essentially qualitative diagnostic procedure. It appears likely that the pathological changes result from accumulation of high concentrations of phytanic acid in the tissues of these patients. In particular, the pathological changes in peripheral nerves probably result from the accumulation of phytanic acid, as demonstrated in sural biopsy (Rake and Saunders, 1966) and necropsy (Alexander, 1966) nerve specimens. Alexander also demonstrated the presence of high levels of phytanic acid in brain, liver, kidney, and heart muscle, indicating the 
diffuse nature of the disease despite the predominance of abnormalities of the nervous system clinically. Laboratory and biochemical evidence of dysfunction of liver, kidney, heart, and skeletal muscle as well as of the nervous system was presented by Richterich, van Mechelen, and Rossi(1965), supporting the impression of extensive organ involvement.

In 1966, Eldjarn, Try, Stokke, Munthe-Kaas, Refsum, Steinberg, Arigan, and Mize, noting the exogenous origin of phytanic acid and the ready conversion of exogenous phytol to phytanic acid, suggested treatment of patients with HAP with a diet low in these two substances.

Considerable light has been shed in recent years on the underlying cause of such abnormal accumulation of phytanic acid in patients with HAP. The isotopic studies of Steinberg and his colleagues (Steinberg, Avigan, Mize, Eldjarn, Try, and Refsum, 1965; Steinberg, Mize, Avigan, Fales, Eldjarn, Try, Stokke, and Refsum, 1966; Steinberg, Vroom, Engel, Cammermeyer, Mize, and Avigan, 1967) indicated that phytanic acid originated in the diet alone, and was not synthesized endogenously, and furthermore that the abnormal accumulation of phytanic acid was due to a defect in the oxidative pathway for its degradation. The precise nature of the defect has been further elucidated by Mize, Herndon, Blass, Milne, Follansbee, Laudat, and Steinberg (1969). The rate of oxidation of phytanic acid in three patients with Refsum's syndrome was found to be less than $5 \%$ of that in normal volunteers (two of these patients were from Northern Ireland, and have been described by Ashenhurst et al. (1958)). Oxidation of alpha-hydroxyphytanic acid, however, was almost normal in these patients, and since this substance is the first to be formed during the alphaoxidation of phytanic acid it was concluded that the defect in Refsum's syndrome lay in the initial step of phytanic acid degradation by alpha-oxidation.

Herndon, Steinberg, Uhlendorf, and Fales (1969) used cultured fibroblasts derived from skin biopsies of patients with HAP for further studies, comparing the metabolic ability of these cells with that of fibroblasts from normal subjects. The heredopathia atactica polyneuritiformis cells were again found to lack the ability to oxidize phytanic acid to alphahydroxy-phytanic acid and further to pristanate. Labelled alpha-hydroxy-phytanic acid and pristanate, however, were normally oxidized by HAP cells. It was concluded that the cells of patients with HAP were deficient in a single enzyme involved in the alpha-hydroxylation of phytanic acid.

The disease appears to be inherited as an autosomal recessive gene (Richterich, Rosin, and Rossi, 1965). No instance of a parent or child of a patient with HAP being affected by the disease has been recorded. The incidence of consanguinity in affected families is high.

The present report concerns three cases of the disease affecting a family of 10 siblings, one of whom died in childhood after a brief illness which was diagnosed as meningitis. No cases have been reported from the Republic of Ireland in the past, $)$ but Ashenhurst, Millar, and Milliken (1958) reported three cases from the North of Ireland and Nevin? et al. a further three cases in 1967. The total of nine $\Rightarrow$ cases for the country as a whole represents a $\stackrel{9}{\square}$ considerable incidence in a small population of some $4 \cdot 3$ million. Cases previously reported have occurred in numerous countries including Norway, $\frac{\text { D }}{\vec{D}}$ Sweden, Great Britain, France, Germany, Holland, 을 Switzerland, Italy, Australia, and the United States, \& totalling less than 50 cases. Richterich, Rosin, and $\vec{\circ}$ Rossi (1965), suggested that the geographical distribution was consistent with common descent from a single Scandinavian stock, disseminated widely through the Viking and later migrations.

The clinical and laboratory features of our three cases are discussed, and the effect of dietary regulation in our single case so far treated in this way is described.

CASE 1

The patient, a 29 year old unmarried female, presentee in March 1969 with a history of increasing weakness of limbs and ataxia for two months, rapidly worsening fue 10 days before admission. She had experienced rhinor $\mathbb{D}$ rhoea for several weeks before the onset of these symps toms. There were no limb pains and there was no subjective loss of sensation. Balance had rapidly deterior- . ated and she was barely able to walk without support. There was no sphincter impairment. She had 'always' had difficulty in perceiving odours, and had been aware of night-blindness since early childhood. Her skin had always been dry and scaly.

Questioning elicited a story of similar symptoms in 1959, when a diagnosis of poliomyelitis had been made, and she had been hospitalized for two months, after which she made a complete recovery. In 1961 a recurrence of symptoms led to readmission to hospital for a further six months, again with eventual recovery. In 1967 a further exacerbation of symptoms occurred. On this occasion she was treated at home. She again recovered gradually. Between these various attacks she was able to undertake and complete her training as a nurse.

On examination she looked thin and ill and weighed $43 \mathrm{~kg}$. The skin was dry and scaly on the trunk and limbs, the appearance being reminiscent of ichthyosis (Fig. 1). Three prominent spider naevi were present on the forehead. There was a mild flexion deformity of both little fingers (Fig. 2). Intelligence was impaired clinically, and an IQ of 77 was later calculated. There was bilateral anosmia and well-marked nystagmus. The visual fields were concentrically constricted to a marked degree, but 


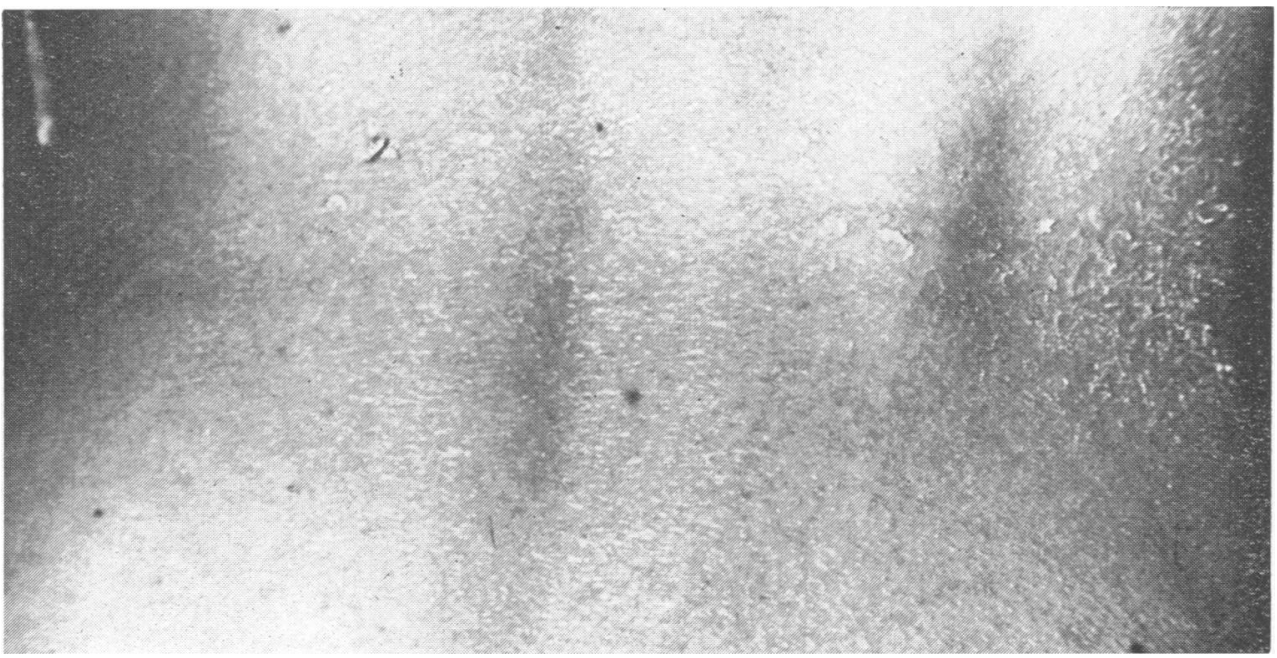

FIG. 1. Ichthyosis-like abnormality of skin.

acuity was well retained. Examination of the fundi revealed well-marked changes of retinitis pigmentosa, with a typical 'bone-spicule' appearance (Fig. 3). The pupils were normal, but there were bilateral fine lenticular opacities. There was no deafness clinically or on audiometry. The cranial nerves were otherwise normal. Abdominal reflexes were normal. Loss of power in the limbs was initially slight, but later became marked and symmetrical, distal muscle groups being chiefly affected. The tendon jerks were absent in the lower limbs, and barely present in the arms. There was distal impairment of all modalities of sensation in all four limbs, extending to the wrists and mid-shin. The ulnar and lateral popliteal nerves were slightly thickened on palpation. Ataxia of all four limbs was present, with impairment of fine movements, marked ataxia on finger-nose and heel-knee testing, and an ataxic gait necessitating support on walking. The plantar responses were normal. Examination of the cardiovascular, respiratory, and gastrointestinal systems was unremarkable.

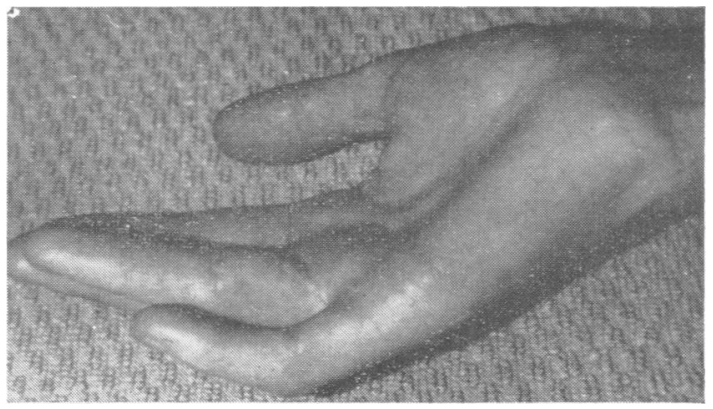

FIG. 2. Flexion deformity of little fingers.
Deterioration continued after admission to hospital, until the patient was unable to rise unaided from a chair, and displayed moderate distal wasting and loss of all tendon reflexes. Limb ataxia and weakness made it impossible for her to feed herself or to light a cigarette without aid.

INVESTIGATIONS Routine estimations of haemoglobin, white cell count, erythrocyte sedimentation rate, and blood electrolytes were normal, as was examination of the urine and urinary chromatography. Liver function tests were normal, including aspartate and alanine aminotransferase levels. The WR was negative. Skull and chest radiographs and electrocardiogram (ECG) were normal. Radiographic survey of the skeleton showed no abnormality. Serum caeruloplasmin was $20 \mathrm{mg} / 100 \mathrm{ml}$. (normal range 27 to $63 \mathrm{mg} / 100 \mathrm{ml}$.). Serum phytanic acid (Professor J. N. Cumings) comprised 14.2\% of serum fatty acids. Electromyography showed clear evidence of denervation of the small muscles of the hands and feet, with gross slowing of motor conduction velocity in the ulnar nerve-to 12 metres/second. Examination of a sural nerve biopsy specimen showed extensive segmental demyelination involving each fibre examined. No hypertrophic changes were noted. Biochemical analysis of the nerve specimen revealed an abnormal lipid which on gas-liquid chromatography occupied the expected area for phytanic acid. Examination of the cerebrospinal fluid showed albuminocytological dissociation, with one lymphocyte/cubic $\mathrm{mm}$, and the remarkable protein level of $1,000 \mathrm{mg} / 100 \mathrm{ml}$.

This patient was treated with a diet containing minimal amounts of phytol and phytanic acid (as outlined by Eldjarn et al, 1966) coupled with vitamin supplements. This treatment was commenced in May 1969, at which time disability was extreme, the patient being unable to stand, sit upright, or perform the simplest tasks, due to a 


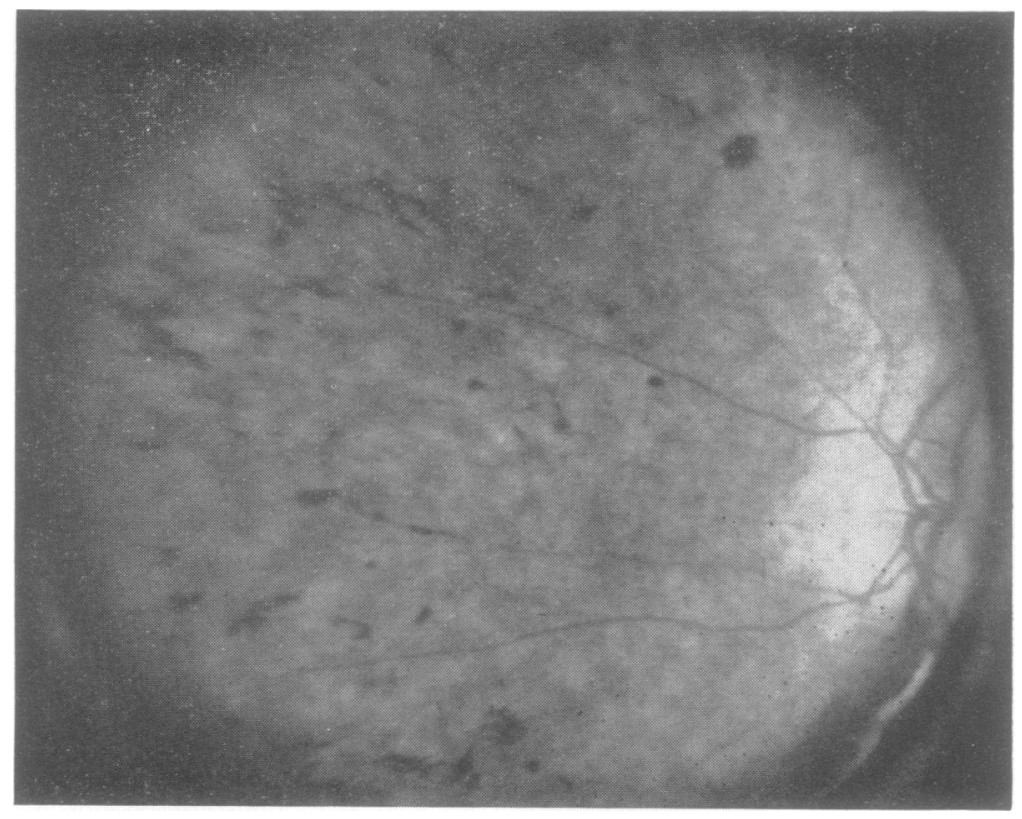

FIG. 3. Retinal appearances.

combination of weakness and ataxia. For some three weeks no change was observed, after which a gradual improvement was observed, progressing to a remarkable degree over the next three months. By late June she was able to walk unaided, albeit unsteadily, and she was discharged from hospital. On review late in August, the skin scaliness had almost entirely disappeared. Her weight had increased from 43 to $52 \mathrm{~kg}$. There was now no perceptible ataxia on walking, but she had difficulty in walking heel-to-toe and was unable to stand on one leg. Slight impairment of coordination was also detectable on finger-nose testing and on evaluation of fine movements. Power was deficient only on flexion-extension of the wrists and extension of the right elbow. Even these movements had $4 / 5$ power. Power elsewhere was normal. No tendon jerks could be elicited, however, and mild impairment of superficial and deep sensation persisted distally, but levels had retreated to metacarpophalangeal joints and ankles. Nystagmus and anosmia were unchanged, as was the degree of retinal pigmentation, and perimetry revealed no improvement in the scope of peripheral vision.

Estimation of serum phytanic acid at this stage showed a reduction to $7.5 \%$ of total fatty acids. The improvement in the clinical state has been maintained up to the time of writing.

\section{CASE 2}

The 28 year old unmarried brother of the propositus attended for examination at our request. In 1956 he had developed 'weakness, numbness, and stiffness' of the left leg, which was again diagnosed as poliomyelitis. Recover was said to be complete after two months in hospita? He denied symptoms of any sort when interviewed. O\& direct questioning there was no history of night-blindness or of difficulty with peripheral vision, but he had had long-standing scaliness of the skin of the face and bot feet.

On examination there was marked scaling of the skin of the face and feet. Pes cavus and flexion deformities of both little fingers were present. The intelligence quotient was estimated as approximately 85 . The ulnar nerves were thickened on palpation, but possibly within normal limits. There was no anosmia nor deafness. The pupils and lenses were normal. The fundi showed clear changes of retinitis pigmentosa, and perimetry showed well-marked concentric constriction of the visual fields. There was nystagmus. Fine movements were poor in both hands, and coordination was impaired on finger-nose testing on the left. The gait appeared normal on walking but there was unsteadiness on walking heel-to-toe, and he was unable to stand on one leg. Rombergism was negative. There was no limb weakness or sensory impairment. Both ankle jerks were absent, the other tendon jerks being normal and the plantar responses flexor. There was no abnormality in the cardiovascular, respira tory, or gastrointestinal systems.

Investigations in this case-and in case 3-were limited by the patient's reluctance to undergo such procedures as lumbar puncture and sural nerve biopsy. Electromyography, however, revealed evidence of denervation in the extensor digitorum brevis muscle, and impaired conduction in the motor fibres of the median 
nerve. Serum phytanic acid was $13 \%$ of total fatty acids, and serum caeruloplasmin $25 \mathrm{mg} / 100 \mathrm{ml}$.

\section{CASE 3}

Case 3, the unmarried 23 year old sister of the preceding two cases, was examined in the course of the family survey. She had no symptoms, neurological or otherwise, and there was no history of previous illness. On questioning, however, she admitted to a long-standing inability to detect or identify odours.

On examination, physique and intelligence were normal. There was bilateral pes cavus, and a flexion deformity of both little fingers. The peripheral nerves were not palpably thickened. There was bilateral anosmia. The retinae showed retinitis pigmentosa of mild degree. Perimetry showed slight concentric constriction of the visual fields. There was well-marked nystagmus. Pupils, lenses, and auditory acuity were normal, and there was no other abnormality in the cranial nerves. Both ankle jerks were absent, and coordination was slightly impaired in the lower limbs. There was slight but definite weakness of all movements at both ankles, but the limbs were otherwise normal and there was no abnormality of gait. Electromyography showed marked slowing of motor conduction in the anterior tibial nerve.

Serum phytanic acid was $8.7 \%$ of total fatty acids, and serum caeruloplasmin $20 \mathrm{mg} / 100 \mathrm{ml}$. Three other siblings and both parents-who were unrelated-were examined. It has so far proved impossible to arrange for the neurological examination of the remaining three male siblings, two of whom are abroad, and all of whom are apparently well. A fine nystagmus was noted in the 70 year old father, but there was no other abnormality. The $\mathbf{5 5}$ year old mother had bilateral flexion deformities of the little fingers, but was otherwise clinically normal. Both had normal skin. No phytanic acid was detected in their sera. The three siblings examined-aged 19, 21, and 30 years-were all symptom free. All displayed a fine nystagmus of doubtful significance, but were otherwise neurologically normal. All had a rather rough dry skin, and all had a flexion deformity of the little fingers, there being no other abnormality in any system. No phytanic acid was detected in their sera. Serum caeruloplasmin levels $/ 100 \mathrm{ml}$. (normal range 27 to $63 \mathrm{mg} / 100 \mathrm{ml}$.) were: father $20 \mathrm{mg}$; mother $66 \mathrm{mg}$; sibs $23 \mathrm{mg}, 22 \mathrm{mg}$, and $40 \mathrm{mg}$, respectively.

\section{DISCUSSION}

The present case reports illustrate the features of Refsum's syndrome, and confirm the importance of phytanic acid as the suggested causative agent in this disease. It is noteworthy that the degree of clinical disability in our cases correlated with the amount of phytanic acid present in the serum, ranging from $8.7 \%$ of total fatty acids (TFA) in case 3 who was asymptomatic and in whom the clinical findings were minimal, to $14.2 \%$ of TFA in case 1 who was initially almost totally disabled.
Furthermore, complete restoration of mobility in case 1 was associated with a fall in phytanic acid level to $7 \cdot 5 \%$ of TFA. Of figures available for comparison, the highest level of phytanic acid noted was by Campbell and Williams (1967) who found a level of $34.7 \%$ of TFA in a case which displayed severe disability. It is tempting to suggest that disability correlates directly with the concentration of phytanic acid, but the finding by Kahlke and Richterich (1965) of a level of $18 \%$ of TFA in the asymptomatic mother of the case of Thiebaut, Lemoyne, and Guillaumat (1961) is not in accord with this view - the level in the mother being as high as that noted in the clinically affected daughter.

No phytanic acid was found in the sera of the parents and unaffected siblings of our three cases, and this accords with the findings of Kahlke and Richterich (1965) in the parents of another case and those of Campbell and Williams (1967) in the parents and relatives of their two cases. Nevin et al. (1967) recorded a level of $2.6 \%$ of TFA in the asymptomatic mother of one of their cases. From these observations it would appear that phytanic acid estimation is likely to be of little value in the identification of carriers of the disease. Its importance lies chiefly in confirming the diagnosis in suspected cases, and in evaluating the effectiveness of dietary treatment.

In respect of diagnosis, however, the case report of Kolodny, Hass, Lane, and Drucker (1965) must be noted. These workers reported a case satisfying clinical criteria for diagnosis of HAP in whose serum no phytanic acid could be identified. The clinical diagnosis was confirmed by Professor Refsum himself, who suggested the adoption of the term 'Refsum's syndrome' for such cases, reserving the appellation of 'Refsum's disease' for those cases in which phytanic acid can be demonstrated.

The observation of levels of phytanic acid of $8.7 \%$ of TFA in our 23 year old case $3,13 \%$ in the 28 year old case 2 , and $14.2 \%$ in the 29 year old propositus before treatment might suggest a gradual increase in phytanic acid accumulation with advancing age, due to continuous dietary ingestion of phytol and phytanic acid. Such gradual accumulation may well occur in the individual case, but older patients do not necessarily display higher levels than younger. Campbell and Williams' 28 year old case 1 had a serum level of $34.7 \%$ of TFA and the patient's 33 year old sister $15 \cdot 6 \%$. Severity of the biochemical defect and residual ability to metabolize phytanic acid (Mize et al, 1969) primarily determine the degree of phytanic acid accumulation, and the onset of the disease in childhood is commonly seen, though few figures of phytanic acid levels in childhood are available. 
Diagnosis of the established syndrome on clinical grounds should present little difficulty, especially where several members of a family are affected. The clinical triad of polyneuritis, cerebellar ataxia, and retinitis pigmentosa as seen in our three cases is characteristic, and unlikely to be mistaken for another disease. This triad was present in all of the 28 cases whose clinical features were reviewed by Richterich, Moser, and Rossi (1965). The pigmentary retinal changes, frequently accompanied by night blindness and visual field impairment, are perhaps the most characteristic clinical feature, and observation of such changes should suggest the diagnosis. However, these changes may not be marked and, since the process of pigmentation and degeneration tends to commence towards the equator, careful ophthalmoscopic examination with dilated pupils should be employed in suspected cases. Retinal changes in our case 3 were confined to the equator, and the visual field defects were correspondingly slight.

Both of our cases who presented with neurological illness were initially diagnosed as poliomyelitis. Several other cases (Ashenhurst et al, 1958; Campbell and Williams, 1967) were initially thought to be suffering from acute infective polyneuritis, a condition which must be closely resembled by Refsum's disease when the changes of polyneuritis predominate, the albuminocytological dissociation in the cerebrospinal fluid appearing to confirm this diagnosis. Ashenhurst et al. (1958) have emphasized the clinical resemblance to Friedreich's ataxia, which was initially diagnosed in one of their cases. Many other conditions may resemble Refsum's disease in some degree, and the differential diagnosis has been discussed in a recent publication (Steinberg et al, 1967). Precise diagnosis is all the more important in view of the promise shown by dietary treatment, and should the results of such treatment continue to be encouraging, sufferers from familial neurological diseases should perhaps be reviewed with special awareness of Refsum's disease. It is conceivable that the disease may be somewhat less rare than is generally thought.

The effectiveness of dietary treatment remains as yet unestablished. The clinical recovery of our case 1 shortly after the institution of a low phytol and phytanic acid diet, and coinciding with a reduction in serum phytanic acid of almost $50 \%$, was quite dramatic. However, the same patient had previously recovered spontaneously from three exacerbations, and recovery on this occasion may merely have coincided with dietary treatment. It may be significant that the patient herself feels that recovery on this occasion was more rapid and more complete than formerly, and that she is herself convinced of the therapeutic efficacy of her diet. Follow-up of this patient for a number of years will be necessary before therapeutic success can legitimately be claimed. Observations on the results of dietary treatment in cases 2 and 3 will also be of interest. It is noteworthy that most improvement in case 1 has occurred in the manifestations of polyneuritis and cerebellar ataxia, as well as in the skin. No improvement has occurred in the degree of retinal pigmentation or visual field defect, and it is likely that these changes are irreversible.

The results of dietary treatment have already been reported by Eldjarn et al. (1966), and Campbell and Williams (1967). The former authors found that serum phytanic acid levels were reduced by up to $80 \%$ in the course of a year's dietary treatment. Both cases treated were found to improve clinically, but in neither case was improvement of considerable degree. It was concluded that many of the abnormalities in these cases were irreversible in view of their long standing. Objective evidence of improvement was noted in one case in that peripheral nerve conduction velocity improved steadily throughout the year of treatment. Campbell and Williams' patient deteriorated steadily over a period of somesix months, despite treatment with a low-phytanic요 acid diet. He subsequently improved considerablyo however, on a diet less restricted than formerly This case also was of many years' standing. These results suggest that dietary treatment is likely to be of less value in long-standing cases.

Various alterations in serum levels of copper and caeruloplasmin have been reported. Richterich et al (1965) found elevated levels of both copper and caeruloplasmin in their single case. Rake and Saunders (1966) noted elevation of caeruloplasmin but a normal copper level in their case. Both values were normal in the two cases investigated by Nevin et al. (1967) but levels of both substances were slightly elevated in non-affected members of the family. Our caeruloplasmin estimations showed diminished levels in all three cases. Levels in the father and two unaffected siblings were also low, but the third sibling had a normal value and that of the mother was somewhat elevated. Hence these results, which would indicate a consistently low caeruloplasmin level in affected persons, are not in accord with previous reports, and no clear pattern emerges.

Our case 1 is, as far as we are aware, the first case reported to date in which dramatic recovery has followed dietary treatment. We have emphasized the real possibility that this recovery was merely coincidental. Our findings are sufficiently encouraging, however, to make further trials of this treatment eminently worthwhile. 
We wish to thank Professor J. N. Cumings for the estimations of phytanic acid, Dr. G. Borrett and Mr. F. McAuley for aid with other investigations, and $\mathrm{Mr}$. Ogilvy and Miss O'Shaughnessy of the photographic and dietetic departments of the Adelaide Hospital for their helpful cooperation.

\section{REFERENCES}

Alexander, W. (1966). Phytanic acid in Refsum's syndrome. J. Neurol. Neurosurg. Psychiat., 29, 412-416.

Ashenhurst, E. M., Millar, J. H. D., and Milliken, T. G. (1958). Refsum's syndrome affecting a brother and two sisters. Brit. med. J., 2, 415-417.

Avigan, J. (1966). The presence of phytanic acid in normal human and animal plasma. Biochim. biophys. Acta., 116, 391-394.

Cammermeyer, J. (1956). Neuropathological changes in hereditary neuropathies: manifestations of the syndrome heredopathia atactica polyneuritiformis in the presence of interstitial hypertrophic polyneuropathy. J. Neuropath. exp. Neurol., 15, 340-361.

Campbell, A., and Williams, E. (1967). Natural history of Refsum's syndrome in a Gloucestershire family. Brit. med. J., 3, 777-779.

Clark, D. B., and Critchley, M. (1951). Heredopathia atactica polyneuritiformis (Refsum's syndrome). Proc. roy. Soc. Med., 44, 689-690.

Eldjarn, L., Try, K., Stokke, O., Munthe-Kaas, A. W., Refsum, S., Steinberg, D., Avigan, J., and Mize, C. (1966). Dietary effects on serum-phytanic-acid levels and on clinical manifestations in heredopathia atactica polyneuritiformis. Lancet, 1, 691-693.

Gordon, N., and Hudson, R. E. B. (1959). Refsum's syndrome. Heredopathia atactica polyneuritiformis. A report of three cases, including a study of the cardiac pathology. Brain, 82, 41-55.

Herndon, J. H. Jr., Steinberg, D., Uhlendorf, B. W., and Fales, H. M. (1969). Refsum's disease: characterization of the enzyme defect in cell culture. J. clin. Invest., 48, 1017-1032.

Kahlke, W., and Richterich, R. (1965). Refsum's disease (heredopathia atactica polyneuritiformis): An inborn error of lipid metabolism with storage of $3,7,11,15$ tetramethyl hexadecanoic acid. Isolation and identification of the storage product. Amer. J. Med., 39, 237-241.

Klenk, E., and Kahlke, W. (1963). Über das Vorkommen der 3, 7, 11, 15-tetramethyl-hexadecansäure (Phytansäüre) in den Cholesterinestern und andern lipoidfraktionen der organe bei einem Krankheitsfall unbekannter Genese (verdacht auf Heredopathia atactica polyneuritiformis (Refsum syndrom)). Hoppe-Seylers Z. Physiol. Chem., 333, 133-139.

Kolodny, E. H., Hass, W. K., Lane, B., and Drucker, W. D. (1965). Refsum's syndrome. Report of a case including electron microscopic studies of the liver. Arch. Neurol. (Chic.), 12, 583-596.

Mize, C. E., Herndon, J. H. Jr., Blass, J. P., Milne, G. W. A. Charlotte Follansbee, Phillippe Laudat, and Daniel Steinberg (1969). Localization of the oxidative defect in phytanic acid degradation in patients with Refsum's disease. J. clin. Invest., 48, 1033-1040.

Nevin, N. C., Cumings, J. N., and McKeown, F. (1967). Refsum's syndrome. Heredopathia atactica polyneuritiformis. Brain., 90, 419-428.

Rake, M., and Saunders, M. (1966). Refsum's disease: a disorder of lipid metabolism. J. Neurol. Neurosurg. Psychiat., 29, 417-422.

Reese, H., and Bareta, J. (1950). Heredopathia atactica polyneuritiformis. J. Neuropath. exp. Neurol., 9, 385-395.

Refsum, S. (1945). Heredoataxia hemeralopica polyneuritiformis-et tidligere ikke beskrevet familiaert syndrom? En foreløbig meddelelse. Nord. Med., 28, 2682-2685.

Refsum, S. (1946). Heredopathia atactica polyneuritiformis. Acta psychiat. neurol. scand., Suppl. No. 38.

Richterich, R., van Mechelen, P., and Rossi, E. (1965). Refsum's disease (heredopathia atactica polyneuritiformis): An inborn error of lipid metabolism with storage of 3, 7, 11, 15-tetramethyl hexadecanoic acid. Report of a case. Amer. J. Med., 39, 230-236.

Richterich, R., Rosin, S., and Rossi, E. (1965). Refsum's disease (heredopathia atactica polyneuritiformis). An inborn error of lipid metabolism with storage of 3,7,11,15tetramethyl hexadecanoic acid. Formal genetics. Humangenetik., 1, 333-336.

Richterich, R., Moser, H., and Rossi, E. (1965). Refsum's disease (heredopathia atactica polyneuritiformis). An inborn error of lipid metabolism with storage of 3,7,11,15tetramethyl hexadecanoic acid. A review of the clinical findings. Humangenetik., 1, 322-332.

Steinberg, D., Avigan, J., Mize, C. E., Eldjarn, L., Try, K., and Refsum, S. (1965). Conversion of U-C14-phytol to phytanic acid and its oxidation in heredopathia atactica polyneuritiformis. Biochem. biophys. res. Commun., 19, 783-789.

Steinberg, D., Mize, C. E., Avigan, J., Fales, H. M., Eldjarn, L., Try, K., Stokke, O., and Refsum, S. (1966). On the metabolic error in Refsum's disease. J. clin. Invest., 45, 1076-1077.

Steinberg, D., Vroom, F. Q., Engel, W. K., Cammermeyer, J., Mize, C. E., and Avigan, J. (1967). Refsum's disease-a recently characterized lipidosis involving the nervous system. Ann. int. Med., 66, 365-395.

Thiebaut, F., Lemoyne, J., and Guillaumat, L. (1961). Maladie de Refsum. Rev. Neurol., 104, 152-154. 